\title{
Donor-acceptor-pair emission characterization in N-B doped fluorescent SiC
}

Ou, Yiyu; Jokubavicius, Valdas; Kamiyama, Satoshi; Liu, Chuan; Berg, Rolf W.; Linnarsson, Margareta; Yakimova, Rositza; Syväjärvi, Mikael; Ou, Haiyan

Published in:

Optical Materials Express

Publication date:

2011

Document Version

Publisher's PDF, also known as Version of record

Link back to DTU Orbit

Citation (APA):

Ou, Y., Jokubavicius, V., Kamiyama, S., Liu, C., Berg, R. W., Linnarsson, M., Yakimova, R., Syväjärvi, M., \& Ou, H. (2011). Donor-acceptor-pair emission characterization in N-B doped fluorescent SiC. Optical Materials Express, 1(8), 1439-1446.

\section{General rights}

Copyright and moral rights for the publications made accessible in the public portal are retained by the authors and/or other copyright owners and it is a condition of accessing publications that users recognise and abide by the legal requirements associated with these rights.

- Users may download and print one copy of any publication from the public portal for the purpose of private study or research.

- You may not further distribute the material or use it for any profit-making activity or commercial gain

- You may freely distribute the URL identifying the publication in the public portal 


\title{
Donor-acceptor-pair emission characterization in N-B doped fluorescent $\mathrm{SiC}$
}

\author{
Yiyu Ou, ${ }^{1, *}$ Valdas Jokubavicius, ${ }^{2}$ Satoshi Kamiyama, ${ }^{3}$ Chuan Liu, ${ }^{4}$ \\ Rolf W. Berg, ${ }^{4}$ Margareta Linnarsson, ${ }^{5}$ Rositza Yakimova, ${ }^{2}$ \\ Mikael Syväjärvi, ${ }^{2}$ and Haiyan $\mathrm{Ou}^{1}$ \\ ${ }^{1}$ Department of Photonics Engineering, Technical University of Denmark, DK-Lyngby 2800, \\ Denmark \\ ${ }^{2}$ Department of Physics, Chemistry and Biology, Linköping University, Linköping SE-58183, \\ Sweden \\ ${ }^{3}$ Faculty of Science and Technology, Meijo University, Nagoya 468-8502, Japan \\ ${ }^{4}$ Department of Chemistry, Technical University of Denmark, Lyngby DK-2800, Denmark \\ ${ }^{5}$ School of Information and Communication Technology, Royal Institute of Technology, Kista \\ SE-16440, Sweden \\ *yiyo@fotonik.dtu.dk
}

\begin{abstract}
In the present work, we investigated donor-acceptor-pair emission in $\mathrm{N}-\mathrm{B}$ doped fluorescent $6 \mathrm{H}-\mathrm{SiC}$, by means of photoluminescence, Raman spectroscopy, and angle-resolved photoluminescence. The photoluminescence results were interpreted by using a band diagram with Fermi-Dirac statistics. It is shown that with $\mathrm{N}$ and $\mathrm{B}$ concentrations in a range of $10^{18} \mathrm{~cm}^{-3}$ the samples exhibit the most intense luminescence when the concentration difference (n-type) is about $4.6 \times 10^{18} \mathrm{~cm}^{-3}$. Raman spectroscopy studies further verified the doping type and concentrations for the samples. Furthermore, strong luminescence intensity in a large emission angle range was achieved from angle-resolved photoluminescence. The results indicate $\mathrm{N}-\mathrm{B}$ doped fluorescent $\mathrm{SiC}$ as a good wavelength converter in white LEDs applications.
\end{abstract}

(C) 2011 Optical Society of America

OCIS codes: (230.3670) Light-emitting diodes; (250.5230) Photoluminescence; (300.6450) Spectroscopy, Raman.

\footnotetext{
References and links

1. H. Yamamoto, "White LED phosphors: the next step," Proc. SPIE 7598, 759808 (2010).

2. P. Schlotter, R. Bompiedi, and J. Schneider, "Luminescence conversion of blue light emitting diodes," Appl. Phys. A 64, 417-418 (1997).

3. X. Guo, J. W. Graff, and E. F. Schubert, "Photon recycling semiconductor light-emitting diode," in Proceedings of IEEE Conference on Electron Devices Meeting (IEEE, 1999), pp. 600-603.

4. E. F. Schubert, Light-Emitting Diodes (Cambridge University Press, 2006).

5. C. Shen, K. Li, Q. Hou, H. Feng, and X. Dong, "White LED based on YAG: Ce, Gd phosphor and CdSe-ZnS core/shell quantum dots," IEEE Photon. Technol. Lett. 22, 884-886 (2010).

6. C. Chang, C. Chen, C. Wu, S. Chang, J. Hung, and Y. Chi, "High-color-rendering pure-white phosphorescent organic light-emitting devices employing only two complementary colors," Org. Electron. 11, 266-272 (2010).

7. R. Mueller-Mach, G. Mueller, M. R. Krames, H. A. Höppe, F. Stadler, W. Schnick, T. Juestel, and P. Schmidt, "Highly efficient all-nitride phosphor-converted white light emitting diode," Phys. Status Solidi A 202, 17271732 (2005).

8. H. Kuo, C. Hung, H. Chen, K. Chen, C. Wang, C. Sher, C. Yeh, C. Lin, C. Chen, and Y. Cheng, "Patterned structure of remote phosphor for phosphor-converted white LEDs," Opt. Express 19, A930-A936 (2011).
}

\#155377 - \$15.00 USD Received 29 Sep 2011; revised 17 Oct 2011; accepted 17 Oct 2011; published 2 Nov 2011

(C) 2011 OSA 1 December $2011 /$ Vol. 1, No. 8 / OPTICAL MATERIALS EXPRESS 1439 
9. H. Menkara, R. A. Gilstrap Jr., T. Morris, M. Minkara, B. K. Wagner, and C. J. Summers, "Development of nanophosphors for light emitting diodes," Opt. Express 19, A972-A981 (2011).

10. H. Zhao, J. Zhang, G. Liu, and N. Tansu, "Surface plasmon dispersion engineering via double-metallic Au/Ag layers for III-nitride based light-emitting diodes," Appl. Phys. Lett. 98, 151115 (2011).

11. T. J. Prosa, P. H. Clifton, H. Zhong, A. Tyagi, R. Shivaraman, S. P. DenBaars, S. Nakamura, and J. S. Speck, "Atom probe analysis of interfacial abruptness and clustering within a single $\operatorname{In}_{x} G a_{1-x} N$ quantum well device on semipolar (101̄1) GaN substrate," Appl. Phys. Lett. 98, 191903 (2011).

12. C. Wetzel and T. Detchprohm, "Wavelength-stable rare earth-free green light-emitting diodes for energy efficiency," Opt. Express 19, A962-A971 (2011).

13. H. Zhao, G. Liu, J. Zhang, J. D. Poplawsky, V. Dierolf, and N. Tansu, "Approaches for high internal quantum efficiency green InGaN light-emitting diodes with large overlap quantum wells," Opt. Express 19, A991-A1007 (2011).

14. X. Li, R. Song, Y. Ee, P. Kumnorkaew, J. F. Gilchrist, and N. Tansu, "Light extraction efficiency and radiation patterns of III-nitride light-emitting diodes with colloidal microlens arrays with various aspect ratios," IEEE Photon. J. 3, 489-499 (2011).

15. J. Zhang, H. Zhao, and N. Tansu, "Effect of crystal-field split-off hole and heavy-hole bands crossover on gain characteristics of high Al-content AlGaN quantum well lasers," Appl. Phys. Lett. 97, 111105 (2010).

16. J. Zhang, H. Zhao, and N. Tansu, "Large optical gain AlGaN-delta-GaN quantum wells laser active regions in mid- and deep-ultraviolet spectral regimes," Appl. Phys. Lett. 98, 171111 (2011).

17. T. Kolbe, A. Knauer, C. Chua, Z. Yang, S. Einfeldt, P. Vogt, N. M. Johnson, M. Weyers, and M. Kneissl, "Optical polarization characteristics of ultraviolet (In)(Al)GaN multiple quantum well light emitting diodes," Appl. Phys. Lett. 97, 171105 (2010).

18. K. Hazu and S. F. Chichibu, "Optical polarization properties of m-plane $A l_{x} G a_{1-x} N$ epitaxial films grown on mplane freestanding GaN substrates toward nonpolar ultraviolet LEDs," Opt. Express 19, A1008-A1021 (2011).

19. J. H. Strait, P. A. George, J. Dawlaty, S. Shivaraman, M. Chandrashekhar, F. Rana, and M. G. Spencer, "Emission of terahertz radiation from SiC," Appl. Phys. Lett. 95, 051912 (2009).

20. G. Xuan, P. C. Lv, X. Zhang, J. Kolodzey, G. Desalvo, and A. Powell, "Silicon carbide terahertz emitting devices," J. Electron. Mater. 37, 726-729 (2008).

21. M. Mirzaei and M. Mirzaei, "A computational study of atomic oxygen-doped silicon carbide nanotubes," J. Mol. Model. 17, 527-531 (2011).

22. S. Choudhary and S. Qureshi, "Theoretical study on transport properties of a BN co-doped SiC nanotube," Phys. Lett. A 375, 3382-3385 (2011).

23. S. Kamiyama, T. Maeda, Y. Nakamura, M. Iwaya, H. Amano, I. Akasaki, H. Kinoshita, T. Furusho, M. Yoshimoto, T. Kimoto, J. Suda, A. Henry, I. G. Ivanov, J. P. Bergman, B. Monemar, T. Onuma, and S. F. Chichibu, "Extremely high quantum efficiency of donor-acceptor-pair emission in $\mathrm{N}$-and-B-doped 6H-SiC," J. Appl. Phys. 99, 093108 (2006).

24. Y. Ou, D. Corell, C. Dam-Hansen, P. Petersen, and H. Ou, "Antireflective sub-wavelength structures for improvement of the extraction efficiency and color rendering index of monolithic white light-emitting diode," Opt. Express 19, A166-A172 (2011).

25. M. Syväjärvi and R. Yakimova, "Sublimation epitaxial growth of hexagonal and cubic SiC," in Encyclopediathe Comprehensive Semiconductor Science and Technology, P. Bhattacharya, R. Fornari, and H. Kamimura, eds. (Elsevier, 2011).

26. D. R. Hamilton, W. J. Choyke, and L. Patrick, "Photoluminescence of nitrogen-exciton complexes in $6 \mathrm{H} \mathrm{SiC,"}$ Phys. Rev. 131, 127-133 (1963).

27. M. Ikeda, H. Matsunami, and T. Tanaka, "Site effect on the impurity levels in $4 \mathrm{H}, 6 \mathrm{H}$, and $15 \mathrm{R}$ SiC," Phys. Rev. B 22, 2842-2854 (1980).

28. W. J. Choyke, D. R. Hamilton, and L. Patrick, "Optical properties of cubic SiC: luminescence of nitrogen-exciton complexes, and interband absorption," Phys. Rev. 133, 1163-1166 (1964).

29. M. Ohishi, "Time-resolved studies on recombination luminescence of donor-acceptor pairs in ZnSe," Jpn. J. Appl. Phys. 25, 1546-1551 (1986).

30. P. Bäume, F. Kubacki, and J. Gutowski, "Characterization of impurities in II-VI semiconductors by time-resolved lineshape analysis of donor-acceptor pair spectra," J. Cryst. Growth 138, 266-273 (1994).

31. V. Grivickas, K. Gulbinas, V. Jokubavicius, Y. Ou, H. Ou, M. Linnarsson, M. Syväjärvi, and S. Kamiyama, "Carrier lifetimes in fluorescent $6 \mathrm{H}-\mathrm{SiC}$ for LEDs application," presented at the Lithuanian National Physics Conference, Vilnius, Lithuania, October 2011.

32. Y. Cheng, G. Lee, P. Chou, L. Chen, Y. Chi, C. Yang, Y. Song, S. Chang, P. Shih, and C. Shu, "Rational design of chelating phosphine functionalized $O s^{(I I)}$ emitters and fabrication of orange polymer light-emitting diodes using solution process," Adv. Funct. Mater. 18, 183-194 (2008).

33. J. Kim, P. Jeon, Y. Park, J. Choi, H. Park, G. Kim, and T. Kim, "White-light generation through ultravioletemitting diode and white-emitting phosphor," Appl. Phys. Lett. 85, 3696-3698 (2004).

34. X. Li, Z. Chen, and E. Shi, "Effect of doping on the Raman scattering of 6H-SiC crystals," Physica B 405, 2423-2426 (2010).

\#155377 - \$15.00 USD Received 29 Sep 2011; revised 17 Oct 2011; accepted 17 Oct 2011; published 2 Nov 2011

(C) 2011 OSA

1 December 2011 / Vol. 1, No. 8 / OPTICAL MATERIALS EXPRESS 1440 
35. G. Irmer, V. V. Toporov, B. H. Bairamov, and J. Monecke, "Determination of the charge carrier concentration and mobility in n-GaP by Raman spectroscopy," Phys. Status Solidi B 119, 595-603 (1983).

36. H. Yugami, S. Nakashima, A. Mitsuishi, A. Uemoto, M. Shigeta, K. Furukawa, A. Suzuki, and S. Nakajima, "Characterization of the free-carrier concentrations in doped $\beta$-SiC crystals by Raman scattering," J. Appl. Phys. 61, 354-358 (1987).

37. D. Sotta, E. Hadji, N. Magnea, E. Delamadeleine, P. Besson, P. Renard, and H. Moriceau, "Resonant optical microcavity based on crystalline silicon active layer," J. Appl. Phys. 92, 2207-2209 (2002).

38. S. S. Pan, C. Ye, X. M. Teng, and G. H. Li, "Angle-dependent photoluminescence of [110]-oriented nitrogendoped $\mathrm{SnO}_{2}$ films,” J. Phys. D: Appl. Phys. 40, 4771-4774 (2007).

\section{Introduction}

To date, white light-emitting diodes (LEDs) are the most promising candidates for the illumination market to replace conventional incandescent lamps as energy-saving and environment friendly light sources. One common method to realize white LEDs is using a UV or blue LED whose light is partially or fully used to optically excite wavelength converters such as dyes, phosphors, and semiconductors [1-4]. Although dyes could have high quantum efficiency, it is lack of long term stability as organic material.

Phosphors are the most common wavelength converters. Recent research on phosphorconverted white LEDs demonstrate very high quantum efficiency of phosphors (larger than $80 \%$ ), controllable correlated color temperature (CCT), and acceptable color rendering index (CRI) value of above 80 [5-9]. However, phosphors usually suffer from a relatively low conversion efficiency in the red color (low ninth CRI value: $R_{9}$ ) which is the main limit to its general CRI value $[6,7,9]$. Therefore, high-efficiency wavelength converters with high CRI value and long lifetime are indispensable.

With large optical bandgap, $\mathrm{SiC}$ can be tailored to emit light across the entire visible spectrum, as well as the near UV region by introducing different dopants. Although $\mathrm{SiC}$ has relatively inefficient light emission compared to the most recent high-efficiency nitride-based visible [10-14] and UV [15-18] LEDs or emitters due to its indirect bandgap, many scientifically interesting applications on impurity-doped $\mathrm{SiC}$ materials have been developed [19-22]. Recently, nitrogen $(\mathrm{N})$ and boron $(\mathrm{B})$ doped $6 \mathrm{H}-\mathrm{SiC}$ has been proven as a highly efficient wavelength converter for white LEDs [23], and internal quantum efficiency as high as $95 \%$ was achieved which shows the better performance than the most common phosphors. Combined donor-acceptor-pair (DAP) band luminescences from N-B and nitrogen-aluminium (N$\mathrm{Al}$ ) doped $6 \mathrm{H}-\mathrm{SiC}$ can cover most of the visible spectral range and thus white light with CRI larger than 90 could be produced [24]. Furthermore, $\mathrm{SiC}$ is a well-established substrate material for nitride growth and has excellent thermal conductivity.

\section{Experiments and results}

To explore how $\mathrm{N}$ and B doping concentrations affect emission, five homoepitaxial layers of $6 \mathrm{H}-\mathrm{SiC}$ with different doping concentrations were grown by Fast Sublimation Growth Process [25]. The growth process is driven by a temperature gradient created between the source, in a form of polycrystalline $\mathrm{SiC}$ plate, and the substrate. Boron was introduced into the epilayers by doping from the source and nitrogen incorporation was controlled by adjusting $N_{2}$ gas pressure during the growth. Epilayers with different concentrations of $\mathrm{B}$ and $\mathrm{N}$ were grown on $6 \mathrm{H}-\mathrm{SiC}$ (0001) substrates with 1.4 degree off-orientation in the [112̄0] direction at growth temperature of $1725^{\circ} \mathrm{C}$. Atomic dopant concentrations of the epilayers measured by secondary ion mass spectrometry (SIMS) are listed in Table 1, where $N_{A}$ and $N_{D}$ represent acceptor (B) and donor (N) concentrations respectively.

\#155377 - \$15.00 USD Received 29 Sep 2011; revised 17 Oct 2011; accepted 17 Oct 2011; published 2 Nov 2011

(C) 2011 OSA 1 December 2011 / Vol. 1, No. 8 / OPTICAL MATERIALS EXPRESS 1441 
Table 1. Boron $\left(N_{A}\right)$ and Nitrogen $\left(N_{D}\right)$ Concentrations for Samples a, b, c, d, and e

\begin{tabular}{lccccc}
\hline & $\mathrm{a}$ & $\mathrm{b}$ & $\mathrm{c}$ & $\mathrm{d}$ & $\mathrm{e}$ \\
\hline$N_{A}\left(10^{18} \mathrm{~cm}^{-3}\right)$ & 8.0 & 6.9 & 6.9 & 4.4 & 5.2 \\
$N_{D}\left(10^{18} \mathrm{~cm}^{-3}\right)$ & 0.04 & 3.2 & 6.0 & 9.0 & 9.2 \\
Conductive type & $\mathrm{p}$ & $\mathrm{p}$ & $\mathrm{p}$ & $\mathrm{n}$ & $\mathrm{n}$ \\
\hline
\end{tabular}

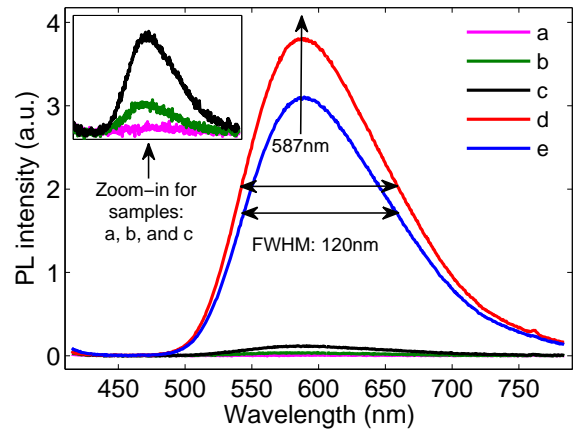

(a)

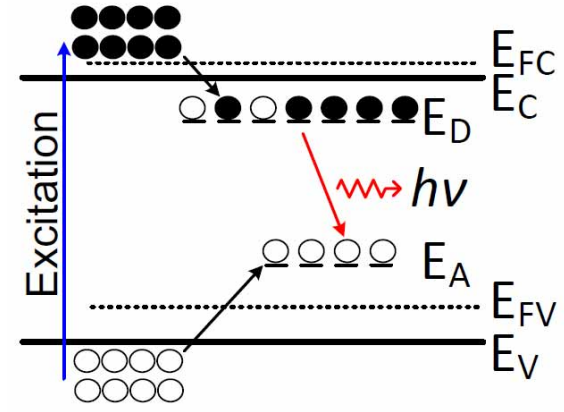

(b)

Fig. 1. (a) Measured PL spectra (inset: zoom-in for sample a, b, and c; PL intensity decreases in the order of d, e, c, b, a), (b) Band diagram of n-type SiC under excitation (black dots represent electrons and unfilled circles represent holes; electron and hole quasi-Fermi levels are represented by $E_{F C}$ and $E_{F V}$ respectively. $E_{D} \approx 0.17 \mathrm{eV}$ [26], $E_{A} \approx 0.72 \mathrm{eV}$ [27], and $E_{g} \approx 3.02 \mathrm{eV}[28]$ ).

\subsection{Photoluminescence}

Photoluminescence (PL) measurements were realized by using a diode laser working at $377 \mathrm{~nm}$ as excitation source which was coupled to a reflected fluorescence microscope. The excitation power density was $0.02 \mathrm{~W} / \mathrm{cm}^{2}$, and the measurements were performed at room temperature. The PL spectra are shown in Fig. 1(a). One can see that the high-level p-type sample (a) exhibits extremely low DAP emission intensity, while the low-level p-type samples $(b, c)$ have relatively stronger DAP emissions but still at a low level. Intense DAP emission was observed in ntype samples (d,e) while the strongest DAP emission occurred in sample d with the largest concentration difference of $4.6 \times 10^{18} \mathrm{~cm}^{-3}$.

Despite the intensity differences, all the DAP emission spectra show the same peak wavelength at $587 \mathrm{~nm}(2.12 \mathrm{eV})$ and the same full width at half maximum (FWHM) of $120 \mathrm{~nm}$. The spectrum shape of the DAP emission is usually determined by the coulomb interaction and phonon coupling rather than by the carrier populations $[29,30]$. Due to the same dopant materials and experimental conditions, the FWHM is almost constant for all the illuminant samples. From the above results, it is clear that both the doping type and the concentration difference affect the DAP emission intensity but do not introduce a change in the peak wavelength and FWHM at this doping level.

The dependence of the DAP emission intensity on doping concentrations could be explained by using band diagram with Fermi-Dirac statistics. Figure 1(b) shows a schematic band diagram of n-type doped $\mathrm{SiC}$ under excitation condition. It is seen that all the acceptor states $\left(E_{A}\right)$ are occupied by photo-excited holes due to the large ionization energy of acceptor states $\left(E_{A}-E_{V}\right)$, 
so the hole density at the acceptor states $p_{A} \cong N_{A}$. On the other hand, the electron density at donor states $\left(E_{D}\right)$ under excitation is given by

$$
n_{D}=N_{D} \cdot F_{D}
$$

due to the small ionization energy $\left(E_{C}-E_{D}\right)$. Here $F_{D}$ is the occupancy probability of an electron on donor states. It can be represented by

$$
F_{D}=\frac{1}{1+\frac{1}{2} \exp \left(\frac{E_{D}-E_{F C}}{k T}\right)} .
$$

where $E_{F C}$ is the electron quasi-Fermi level under excitation, $k$ is the Boltzmann constant, and $T$ is the absolute temperature.

The DAP recombination rate $R_{D A}$ is proportional to the product of $p_{A}$ and $n_{D}$, hence,

$$
R_{D A} \propto N_{D} \cdot F_{D} \cdot N_{A} .
$$

Large donor and acceptor doping concentrations are required to achieve intense DAP recombination according to Eq. (3). In addition, the n-type sample is more likely to achieve high electron density at donor states. That is because, $E_{F C}$ is at a higher energy level in the n-type samples than in the p-type ones. When $N_{A}$ of the samples are in the same level and the concentration difference $\left(N_{D}-N_{A}\right)$ increases, $E_{F C}$ becomes larger and could be within the conduction band. As a result, $F_{D}$ increases and a high electron density could be generated at donor states. This is in good accordance with our PL measurement results.

Carrier lifetime measurements of the samples were carried out by using $355 \mathrm{~nm}, 2 \mathrm{~ns}, 40$ $\mathrm{Hz}$ laser pulses in the work [31]. The obtained carrier lifetimes from sample a to e are 0.5 ns, $30 \mathrm{~ns}, 0.5 \mu \mathrm{s}, 1.2 \mu \mathrm{s}$, and $1.1 \mu \mathrm{s}$ respectively. Combined with PL results, it is found that the longer carrier lifetime is responsible for stronger emission intensity. Sample $d$ with the largest concentration difference of $N_{D}-N_{A}$ has the longest carrier lifetime of $1.2 \mu \mathrm{s}$, which is comparable to the values of common phosphors: $0.89 \mu$ s in Ref. [32] and $1.4 \mu$ s in Ref. [33].

However, very high $N_{D}-N_{A}$ will cause intra-band absorption of excitation light and severe Auger recombination, both of which reduce the emission efficiency. So optimal concentrations need to be further studied.

\subsection{Raman spectroscopy}

Raman scattering spectra of the $6 \mathrm{H}-\mathrm{SiC}$ samples were acquired in a backscattering configuration using the $514.5 \mathrm{~nm}$ line from an Ar ion laser (5 mW). Longitudinal optical (LO) modes of the Raman spectra are shown in Fig. 2, and the mechanisms of the observed Raman shifts in pand n-type samples are different.

In p-type samples, very few acceptor states are ionized due to the large ionization energy, and the Raman shift is mainly attributed to the atomic size effect [34]. Boron atoms usually are believed to occupy $\mathrm{Si}$ lattice positions in $\mathrm{SiC}$. The interatomic distance of a $\mathrm{Si}-\mathrm{C}$ bond is longer than that of a B-C bond due to the smaller atomic radius of $\mathrm{B}$. The biaxial tensile stress will be released which results in a decrease of the phonon oscillation frequency. So the LO mode shifts toward smaller wavenumbers with higher B concentrations.

In n-type samples, the predominant mechanism causing the Raman shift of the LO mode is the coupling interaction between LO phonons and overdamped plasmons [35,36].

The plasmon frequency $\omega_{P}$ is given by

$$
\omega_{P}=\sqrt{\frac{4 \pi n e^{2}}{\varepsilon_{\infty} m^{*}}},
$$

\#155377 - \$15.00 USD Received 29 Sep 2011; revised 17 Oct 2011; accepted 17 Oct 2011; published 2 Nov 2011

(C) 2011 OSA

1 December 2011 / Vol. 1, No. 8 / OPTICAL MATERIALS EXPRESS 1443 


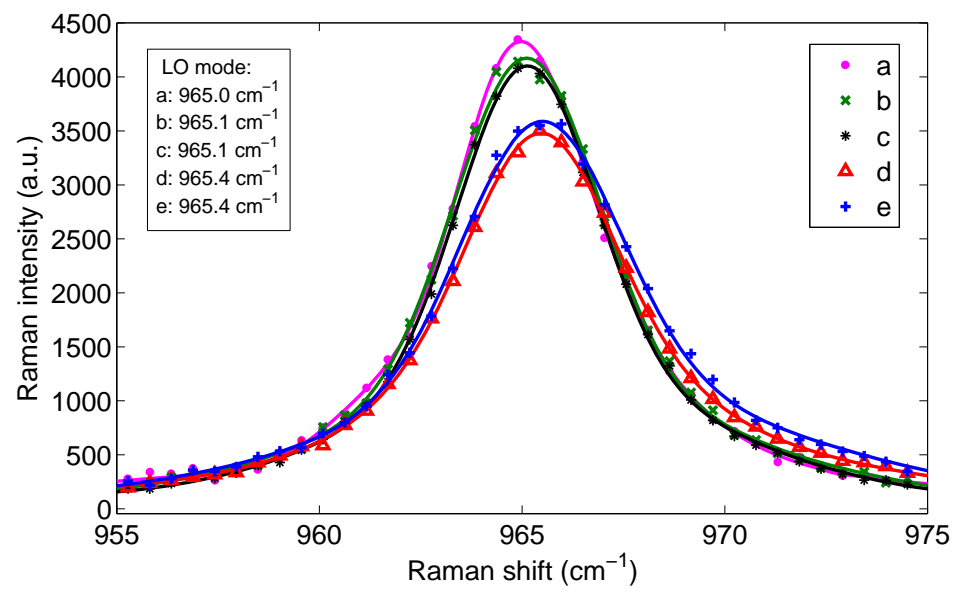

Fig. 2. LO mode of the Raman spectra (inset: positions of LO modes; peak height decreases in the order of $a, b, c, e, d)$.

where $n, e, \varepsilon_{\infty}$, and $m^{*}$ are the free carrier concentration, electron charge, optical dielectric constant, and effective mass of electron respectively. The LO mode is then redefined as longitudinal optical phonon-plasmon coupled (LOPC) mode.

From Eq. (4), it is seen that $\omega_{P}$ is proportional to $\sqrt{n}$. So the plasmon frequency increases with increasing the free electron concentration, which results in an enhancement of the coupling interaction between phonons and plasmons. Consequently, the LOPC mode would lower its intensity and shift toward higher wavenumbers. Usually, the LOPC mode is more sensitive to the presence of free electrons than to the free holes. This is in a good agreement with the results shown in Fig. 2, where the LOPC modes of n-type samples occur at significantly higher wavenumbers than the p-type ones. Although no obvious peak shift has been observed between sample $\mathrm{d}$ and e due to the relatively small concentration difference, the peak intensity of the LOPC mode decreases as expected when the free electron concentration $\left(N_{D}-N_{A}\right)$ increases from sample e to $d$.

\subsection{Angle-resolved photoluminescence}

Angle-resolved PL was measured on sample d by using a goniometer. The excitation light was fixed to a certain direction, and the observation (emission) angle varied from 0 (normal to the sample surface) to 80 degrees. From the acquired spectra shown in Fig. 3(a), one can see that the PL intensity decreases and its peak shifts toward shorter wavelength as the emission angle $\theta$ increases.

The PL intensity becomes lower because the internal reflection increases as the emission angle increases, hence, the emission light extracted out of the $\mathrm{SiC}$ sample decreases. From Fig. 3 (b), it is also seen that the luminescence intensity at an angle of 80 degrees is still around 57 $\%$ of the one normal to the surface, which is quite promising among the most of commercial LEDs (less than $30 \%$ ).

In addition, this angular-dependent PL peak wavelength is attributed to the Fabry-Pérot microcavity interference effect, and similar phenomena have also been observed in Refs. [37,38].

The Fabry-Pérot equation

$$
m \lambda=2 d n \cos \psi .
$$

gives the condition for constructive interference of light undergoing multiple internal reflec-

\#155377 - \$15.00 USD Received 29 Sep 2011; revised 17 Oct 2011; accepted 17 Oct 2011; published 2 Nov 2011

(C) 2011 OSA 1 December 2011 / Vol. 1, No. 8 / OPTICAL MATERIALS EXPRESS 1444 


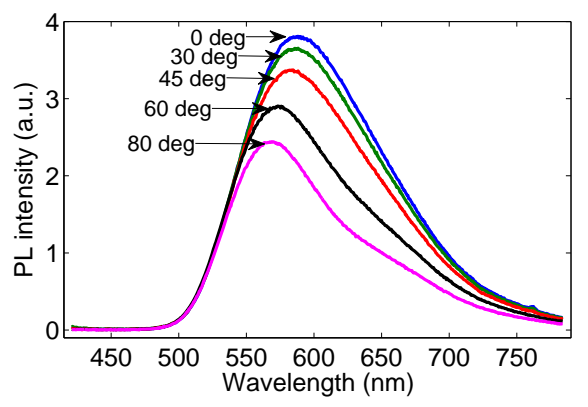

(a)

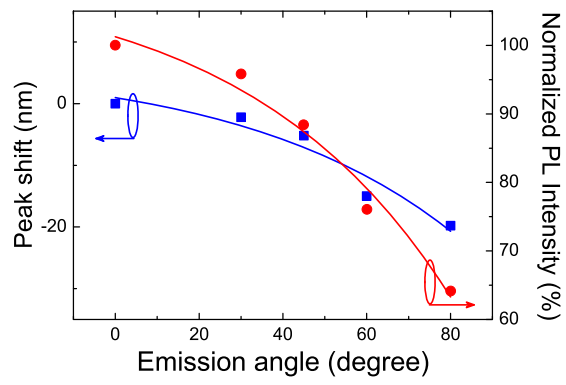

(b)

Fig. 3. (a) Angular-dependent PL spectra, (b) emission angle versus peak shift and normalized PL intensity (\%).

tions in a solid film or an étalon. In Eq. (5), $m$ is the interference order, $\lambda$ is the propagating wavelength, $d$ is the étalon thickness, $n$ is the refractive index of the étalon, and $\psi$ is the wavefront propagation angle with respect to the surface normal. The relationship between $\psi$ and $\theta$ can be represented by Snell's law

$$
n \sin \psi=\sin \theta .
$$

Thus, the Fabry-Pérot equation can be rewritten as

$$
m \lambda=2 d \sqrt{n^{2}-\sin ^{2} \theta} .
$$

The N-B doped $\mathrm{SiC}$ film grown on the $6 \mathrm{H}-\mathrm{SiC}$ substrate has a large refractive index difference at the SiC-air interface. Also due to its smooth surface, it acts as a Fabry-Pérot étalon and thus optical interference occurs. The DAP emission in SiC is broad as shown in the PL spectra. From Eq. (7), it is clear that the interference wavelength decreases as $\theta$ increases. The PL peak shifts toward shorter wavelengths as the emission angle increases and this is consistent with the observed results.

However, for the illumination application, the light source should not depend on the emission angle in terms of the peak wavelength. To improve it, nanostructuring of the surface to remove the Fabry-Pérot interference and increase the luminescence intensity at large emission angle should be interesting to study for a comparison.

\section{Conclusion}

In conclusion, five fluorescent $\mathrm{SiC}$ samples with varied $\mathrm{B}$ and $\mathrm{N}$ doping concentrations were investigated. It is found that $\mathrm{n}$-type doping with both $\mathrm{B}$ and $\mathrm{N}$ concentrations larger than $10^{18}$ $\mathrm{cm}^{-3}$ is required to achieve intense DAP emission, and the concentration difference of the ntype sample needs to be larger than $4 \times 10^{18} \mathrm{~cm}^{-3}$ as concluded from this study. The doping type and concentrations of the samples were then confirmed by analyzing the LO mode variation in Raman spectra.

The luminescence intensity at an emission angle of 80 degrees is found to be $57 \%$ of the one normal to the surface. Angular-dependent PL spectra which arised from the Fabry-Pérot microcavity interference effect was also observed and expected to be removed by applying surface nanostructuring. With adjustment of doping concentrations, intense DAP emission with a broad spectral range was obtained making fluorescent $\mathrm{SiC}$ a good candidate of a wavelength converter in white LEDs. 


\section{Acknowledgments}

This work was supported by the Danish councils for strategic research funding (no. 09-072118) and the Agency for Science, Technology and Innovation (no. 09-065038), Swedish Energy Agency, Nordic Energy Research, Swedish Research Council (no. 2009-5307), Department of the New Energy and Industrial Technology Development Organization. Y. O. also thanks Dr. Y. Chen from DTU Fotonik for the valuable discussion.

\#155377 - \$15.00 USD Received 29 Sep 2011; revised 17 Oct 2011; accepted 17 Oct 2011; published 2 Nov 2011

(C) 2011 OSA

1 December 2011 / Vol. 1, No. 8 / OPTICAL MATERIALS EXPRESS 1446 